\title{
Water based pillows reduced pain and improved sleep and disability in patients with cervical pain
}

Lavin RA, Pappagallo M, Kuhlemeier KV.Cervical pain: a comparison of three pillows. Arch Phys Med Rehabil 1997 Feb;78:193-8.

\section{Objective}

To compare standard, cervical roll, and water based pillows for pain intensity, pain relief, quality of sleep, disability, and satisfaction in patients with benign cervical pain.

\section{Design}

5 week, randomised controlled, crossover trial.

\section{Setting}

Outpatient neurology and psychiatry clinics in a university hospital in the USA.

\section{Patients}

46 patients with neck pain were recruited through a newspaper advertisement. Exclusion criteria were a history of dementia, neoplasm, or known infection in the cervical region. 41 patients (mean age $48 \mathrm{y}, 51 \%$ women) completed the study.

\section{Intervention}

Patients used their usual pillow during the first week and were allocated to either a cervical roll pillow (Cervi-Garde, model 1540) $(\mathrm{n}=19)$ or water based pillow (Mediflow) $(\mathrm{n}=22)$ for 2 weeks. They changed experimental pillows for the next 2 weeks. The standard pillow was filled with down or foam. The cylindrical roll pillow was polyester fibre filled and measured $43 \mathrm{~cm}$ by $18 \mathrm{~cm}$. The water based pillow was constructed using $10 \mathrm{~cm}$ of polyester fibre over an insulated $3.8 \mathrm{~cm}$ water filled pouch (2360 $\mathrm{ml}$ of water). The water volume could be adjusted to change the firmness of the pillow.

\section{Main outcome measures}

Self reported scores in daily diaries and a daily questionnaire were used to assess pain intensity, pain relief, and quality of sleep. Pain scores were ascertained before sleep and after awakening and sleep quality was assessed after awakening. Satisfaction and level of function (Sickness Impact Profile) were evaluated at the end of each 2 week period.

\begin{abstract}
Main results
The water pillow showed lower morning pain intensity scores compared with standard $(\mathrm{p}<0.025)$ and roll pillows $(\mathrm{p}<0.005)$. The water pillow had greater pain relief scores compared with the roll pillow for morning $(\mathrm{p}<0.01)$ and evening $(\mathrm{p}<0.05)$ assessments. Rank ordering of the quality of sleep variables and overall satisfaction showed that the water pillow was first, then the roll pillow and standard pillow. The standard and water pillows allowed longer duration of sleep than the roll pillow $(\mathrm{p}<0.05)$. The water based pillow was better for overall satisfaction than the other pillows $(\mathrm{p}<0.001)$. The Sickness Impact Profile also showed that patients who used the water pillow reported less disability than patients who used the roll pillow $(\mathrm{p}<0.025)$ or the standard pillow $(\mathrm{p}<0.01)$.
\end{abstract}

\section{Conclusion}

Patients with cervical pain who used a water based pillow reported lower pain scores, greater pain relief, greater sleep quality, higher satisfaction, and less disability than patients who used standard or cervical roll pillows.

Source of funding: Mediflow Water Pillow, Ltd.

For article reprint: $\operatorname{Dr} R$ A Lavin, Department of Physical Medicine and Rehabilitation, Good Samaritan Professional Office Building, Suite 406, 5601 Loch Raven Boulevard, Baltimore, MD, 21239, USA. Fax +1 4105324719

\section{Commentary}

This randomised trial by Lavin et al attempts to provide an objective comparison of the use of 3 different pillows for relief of cervical pain. The use of a variety of measurement tools has reduced much of the potential subjectivity of the results, and has left a clear pathway to follow for comparison of other pillows.

The methods of the study include thorough selection criteria. Future comparison studies may wish to consider the sex issues surrounding sleep, and the recognised changes in sleep patterns attributable to advancing age. ${ }^{1}$ The authors acknowledge the potential bias toward the roll and water pillows in the length of the trial given to each, and the reader needs to be aware of the source of funding for the study.

In an area where little work has been done, this is a good introductory study. With a move away from the medical model of care, this adjunct to more traditional treatments sits well within the role of the nurse in promoting patient comfort and should be considered when assessing a patient with cervical pain. Because a large proportion of the population has cervical pain, the evaluation and appropriate use of pillows to reduce pain, with a subsequent improvement in the duration of sleep, is useful beyond the confines of a health care setting.
Further work into comparisons of other pillow types would seem to be a natural progression from this study, and any continued benefits shown in the relief of cervical pain and its effect on sleep and disability would be most welcome.

Heather M Monaghan, RGN Clinical Nurse Advisor, United Leeds Teaching Hospitals National Health Services Trust Leeds, UK

1 Closs J. Patients sleep-wake rhythms in hospital. Part 1. Nurs Times 1988;84:48-50. 